Journal of Engineering and Applied Sciences 14 (Special Issue 8): 10452-10458, 2019

ISSN: 1816-949X

(C) Medwell Journals, 2019

\title{
Differential Subordination and Superordination for Univalent Meromorphic Functions Involving Cho-Kwon-Srivastava Operator
}

\author{
Asraa Abdul Jaleel Husien \\ Technical Institute of Al-Diwaniya, Al-Furat Al-Awsat Technical University, \\ Diwaniya, Iraq
}

Abstract: Using a Cho-Kwon-Srivastava operator, we introduce and study some differential subordination and superordination results for univalent meromorphic functions in the punctured open unit disk $\mathrm{U}^{*}$.

Key words: Univalent meromorphic function, subordination, super ordination, Cho-Kwon-Srivastava operator, admissible functions, investigating classes

\section{INTRODUCTION}

Let, $\mathrm{D}(\mathrm{U})$ be the class of analytic functions in the open unit disk $U=\{z \in \mathbb{C}:|z|<1\}$ and $D[\sigma, n]$ be the subclass of $\mathrm{D}(\mathrm{U})$ consisting of functions of the form $\mathrm{f}(\mathrm{z})=\sigma+\sigma_{\mathrm{n}} \mathrm{z}^{\mathrm{n}}+\sigma_{\mathrm{n}+1} \mathrm{z}^{\mathrm{n}+1}+\ldots$, with $\mathrm{D}_{0}=\mathrm{D}[0,1]$ and $\mathrm{D}_{1}=$ $\mathrm{D}[1,1]$. Let $f$ and $g$ members of $\mathrm{D}(\mathrm{U})$. The function $f$ is said to be subordinate to $\mathrm{g}$ in U written $f \prec \mathrm{g}$ or $f(\mathrm{z}) \prec \mathrm{g}(\mathrm{z})$ $(z \in U)$, if there exists a Schwarz function $w(z)$ is analytic in $\mathrm{U}$ with $\mathrm{w}(0)=0$ and $|\mathrm{w}(\mathrm{z})|<1$ in $\mathrm{U}$ such that $f(z)=g(w(z))(z \in U)$ (Bulboaca, 2005; Miller and Mocanu, 2000). In particular, if the function $g$ is univalent in $\mathrm{U}$, then, we have the following equivalence:

$$
f(\mathrm{z}) \prec \mathrm{g}(\mathrm{z}) \Leftrightarrow f(0)=\mathrm{g}(0) \text { and } f(\mathrm{U}) \subset \mathrm{g}(\mathrm{U})
$$

In order to prove the results, we shall need the following definition and theorem.

Definition (1.1); Miller and Mocanu (2000): Denote by $Q$ the set of all functions that are analytic and injective on $\overline{\mathrm{U}} \mathrm{E}(\mathrm{q})$ where:

$$
\mathrm{E}(\mathrm{q})=\left\{\zeta \in \partial \mathrm{U}: \lim _{\mathrm{z} \rightarrow \zeta} \mathrm{q}(\mathrm{z})=\infty\right\}
$$

And are such that $\mathrm{q}^{\prime}(\zeta) \neq 0$ for $\zeta \in \partial \mathrm{UE}(\mathrm{q})$. Further let the subclass of $Q$ for which $q(0)=\sigma$ be denoted by $Q(\sigma)$, $\mathrm{Q}(0) \equiv \mathrm{Q}_{0}$ and $\mathrm{Q} 1(1) \equiv \mathrm{Q}_{1}$ :

Definition (1.2); Miller and Mocanu (2000): Let $\Omega$ be a set in $\mathbb{C} \in \mathrm{Q}$ and let $\mathrm{n}$ be a positive integer. The class of admissible functions $\Psi_{\mathrm{n}}[\Omega, \mathrm{q}]$ consists of those functions $\psi: \mathbb{C}^{3} \times \mathrm{U} \rightarrow \mathbb{C}$ that satisfy the admissibility condition $\psi(\mathrm{r}, \mathrm{s}, \mathrm{t} ; \mathrm{z}) \notin \Omega$ whenever $\mathrm{r}=\mathrm{q}(\zeta), \mathrm{s}=\mathrm{k} \zeta \mathrm{q}^{\prime}(\zeta)$ and:

$$
\operatorname{Re}\left\{\frac{\mathrm{t}}{\mathrm{s}}+1\right\} \geq \operatorname{ke}\left\{\frac{\zeta \mathrm{q}^{\prime \prime}(\zeta)}{\mathrm{q}^{\prime}(\zeta)}+1\right\}
$$

$\mathrm{z} \in \mathrm{U}, \quad \zeta \in \partial \mathrm{U} \backslash \mathrm{E}(\mathrm{q}), \mathrm{k} \geq \mathrm{n}$. We write $\psi_{1}[\Omega, \mathrm{q}]$ as $\psi[\Omega, q]$. In particular when $\mathrm{q}(\mathrm{z})=\mathrm{M} \frac{\mathrm{Mz}+\sigma}{\mathrm{M}+\overline{\sigma z}}$ with $\mathrm{M}>0$ and $|\sigma|<\mathrm{M}$, then $\mathrm{q}(\mathrm{U})=\mathrm{U}_{\mathrm{M}}=\{\mathrm{w}:|\mathrm{w}|<\mathrm{M}\}, \mathrm{q}(0)=\sigma, \mathrm{E}(\mathrm{q})=\varphi$ and $\mathrm{q} \in \mathrm{Q}(\sigma)$. In this case, we set $\psi_{\mathrm{n}}[\Omega, \mathrm{M}, \sigma]=\psi_{\mathrm{n}}[\Omega, \mathrm{q}]$ and in the special case when $\Omega=\mathrm{U}_{\mathrm{M}}$ the class is simply denoted by $\psi_{\mathrm{n}}[\mathrm{M}, \sigma]$.

Definition (1.3); Miller and Mocanu (2003): Let $\Omega$ be a set in $\mathbb{C}, \mathrm{q} \in \mathrm{D}[\sigma, \mathrm{n}]$ with $\mathrm{q}^{\prime}(\mathrm{z})=0$. The class of admissible functions $\psi^{\prime}{ }_{n}[\Omega, q]$ consists of those functions $\psi: \mathbb{C}^{3} \times \overline{\mathrm{U}} \rightarrow \mathbb{C}$ that satisfy the admissibility condition $\psi(\mathrm{r}$, $\mathrm{s}, \mathrm{t} ; \zeta) \in \Omega$ whenever $\mathrm{r}=\mathrm{q}(\mathrm{z}), \mathrm{s}=\frac{\mathrm{zq}(\mathrm{z})}{\mathrm{m}}$ and:

$$
\operatorname{Re}\left\{\frac{\mathrm{t}}{\mathrm{s}}+1\right\} \leq \frac{1}{\mathrm{~m}} \operatorname{Re}\left\{\frac{\mathrm{zq}^{\prime \prime}(\mathrm{z})}{\mathrm{q}^{\prime}(\mathrm{z})}+1\right\}
$$

$\mathrm{z} \in \mathrm{U}, \zeta \in \partial \mathrm{U}, \mathrm{m} \geq \mathrm{n} \geq 1$. We write $\psi^{\prime}{ }_{1}[\Omega, \mathrm{q}]$ as $\psi^{\prime}[\Omega, \mathrm{q}]$.

Theorem (1.4); Miller and Mocanu (2000): Let $\psi \in \Psi_{\mathrm{n}}[\Omega, \mathrm{q}]$ with $\mathrm{q}(0)=\sigma$. If the analytic function $\mathrm{p}(\mathrm{z})=$ $\sigma+\sigma_{n} z^{n}+\sigma_{n+1} z^{n+1}+\ldots(z \in U)$ satisfies the following inclusion relationship:

$$
\psi\left(\mathrm{p}(\mathrm{z}), \mathrm{zp}^{\prime}(\mathrm{z}), \mathrm{z}^{2} \mathrm{p}^{\prime \prime}(\mathrm{z}) ; \mathrm{z}\right) \in \Omega
$$

Then:

$$
\mathrm{p}(\mathrm{z}) \prec \mathrm{q}(\mathrm{z})(\mathrm{z} \in \mathrm{U})
$$

Theorem (1.5); Miller and Mocanu (2003): Let $\psi \in \Psi^{\prime}{ }_{n}[\Omega, q]$ with $\mathrm{q}(0)=\sigma$. If $\mathrm{p}(\mathrm{z}) \in \mathrm{Q}(\sigma)$ and $\psi\left(\mathrm{p}(\mathrm{z}), \mathrm{zp} \mathrm{p}^{\prime}(\mathrm{z})\right.$, $\left.\mathrm{z}^{2} \mathrm{p}^{\prime \prime}(\mathrm{z}) ; \mathrm{z}\right)$ is univalent $\mathrm{U}$ then: 


$$
\Omega \subset\left\{\psi\left(p(z), z p^{\prime}(z), z^{2} p^{\prime \prime}(z) ; z\right)\right\}
$$

Implies:

$$
\mathrm{p}(\mathrm{z}) \prec \mathrm{q}(\mathrm{z})(\mathrm{z} \in \mathrm{U})
$$

Let $\sum$ denote the class of meromorphic functions $\mathrm{f}(\mathrm{z})$ normalized by:

$$
f(z)=\frac{1}{z}+\sum_{n=1}^{\infty} \sigma_{n} z^{n}
$$

Which are analytic in the punctred unit disk $\mathrm{U}^{*}=\{\mathrm{z} \in \mathbb{C}: 0<|\mathrm{z}|<1\}=\mathrm{U} \backslash\{0\}$. For function $\mathrm{f}(\mathrm{z}) \in \sum$ given by (Eq. 1) and $g(z) \in \sum$ defined by:

$$
\mathrm{g}(\mathrm{z})=\frac{1}{\mathrm{z}}+\sum_{\mathrm{n}=1}^{\infty} \mathrm{a}_{\mathrm{n}} \mathrm{z}^{\mathrm{n}}
$$

The Hadamard product (or convolution) of $\mathrm{f}(\mathrm{z})$ and $\mathrm{g}(\mathrm{z})$ is given by:

$$
(f * g)(z)=(g * f)(z)=\frac{1}{z}+\sum_{n=1}^{\infty} \sigma_{n} a_{n} z^{n}
$$

Let us define the function $\tilde{\phi}(\alpha, \beta: z)$ by:

$$
\tilde{\phi}(\alpha, \beta: z)=\frac{1}{z}+\sum_{n=1}^{\infty}\left|\frac{(\alpha) n+1}{(\beta) n+1}\right| z^{n}
$$

For $\beta \neq 0,-1,12, \ldots$ and $\alpha \in \mathbb{C} /\{0\}$ where $\lambda_{n}=\lambda(\lambda+1)_{n+1}$ is the Pochhammer symbol. We note that:

$$
\tilde{\phi}(\alpha, \beta: z)=\frac{1}{z}{ }_{2} F_{1}(1, \alpha, \beta ; z)
$$

Where:

$$
{ }_{2} F_{1}(1, \alpha, \beta ; z)=\sum_{n=1}^{\infty} \frac{(a)_{n}(b)_{n}}{(c)_{n}} \frac{z^{n}}{n !}
$$

Is the well-known Gaussian hypergeometric function. Let us put:

$$
\mathrm{q}_{\lambda, \mu}(\mathrm{z})=\frac{1}{\mathrm{z}}+\sum_{\mathrm{n}=1}^{\infty}\left(\frac{\lambda}{\mathrm{n}+1+\lambda}\right)^{\mu} \mathrm{z}^{\mathrm{n}},(\lambda>0, \geq 0)
$$

Corresponding to the functions $\tilde{\phi}(\alpha, \beta ; z)$ and $q_{\lambda, \mu}(z)$ and using the Hadamard product for $\mathrm{f}(\mathrm{z} \in \Sigma)$ we defined a linear operator $\mathrm{L}(\alpha, \beta, \lambda, \mu)$ (Ghanim and Darus, 2011a, b) on $\sum$ by:

$$
\mathrm{L}(\alpha, \beta, \lambda, \mu) \mathrm{f}(\mathrm{z})=\left(\mathrm{f}(\mathrm{z}) * \tilde{\phi}(\alpha, \beta: \mathrm{z}) * \mathrm{q}_{\lambda, \mu}(\mathrm{z})\right)
$$

$$
=\frac{1}{z}+\sum_{n=1}^{\infty}\left|\frac{(\alpha) n+1}{(\beta) n+1}\right|\left(\frac{\lambda}{n+1+\lambda}\right)^{\mu} \sigma_{n} z^{n}
$$

The meromorphic functions with the generalized hypergeometric functions were considered recently by Dziok and Srivastava (2002, 2003); Liu (2001; 2003); Liu and Srivastava (2001; 2004a, b); Cho and Kim (2007). For a function $\mathrm{f}(\mathrm{z}) \in \mathrm{L}(\alpha, \beta, \lambda, \mu)$ we define:

$$
\mathrm{I}_{\alpha, \beta, \lambda}^{\mu 0}=\mathrm{L}(\alpha, \beta, \lambda, \mu) \mathrm{f}(\mathrm{z})
$$

And for $\mathrm{k}=1,2, \ldots$, :

$$
\begin{aligned}
& \mathrm{I}_{\alpha, \beta, \lambda}^{\mu, 0}=\mathrm{z}\left(\mathrm{I}^{\mathrm{K}-\mathrm{l}} \mathrm{L}(\alpha, \beta, \lambda, \mu) \mathrm{f}(\mathrm{z})\right)^{\prime}+\frac{2}{\mathrm{z}}= \\
& \frac{1}{\mathrm{z}}+\sum_{\mathrm{n}=1}^{\infty} \mathrm{n}^{\mathrm{k}} \mid \frac{(\alpha) \mathrm{n}+1}{(\beta) \mathrm{n}+1}\left(\frac{\lambda}{\mathrm{n}+1+\lambda}\right)^{\mu} \sigma_{\mathrm{n}} \mathrm{z}^{\mathrm{n}}
\end{aligned}
$$

Not that if $\mathrm{n}=\beta, \mathrm{k}=0$ the operator $\mathrm{I}_{\alpha, \mathrm{n}, \lambda}^{\mu, 0}$ have been introduced by Cho et al. (2004) for $\mu \in \mathrm{N}_{0}=\mathrm{N} \cup 0$. It was known that the definition of the operator $I_{\alpha, n, \lambda}^{\mu, 0}$ was motivated essentially by Choi et al. (2002) for analytic functions which includes a simpler integral operator studied earlier by Noor (1999) and others Liu (2001); Liu and Noor (2002). Note also the operator $I_{\alpha, \beta}^{0, k}$ have been recently introduced and studied by Ghanim and Darus (2010a, b; 2011). To our best knowledge, the recent work regarding $I_{\alpha, \mathrm{n}, \lambda}^{\mu, 0}$ was charmingly studied by Piejko and Sokol (2008). In the same direction, we will study for the operator $I_{\alpha, \beta, \lambda}^{\mu, k}$ given in Eq. 6. Now, it follows from Eq. 5 and 6 that:

$$
\begin{aligned}
& \left.z\left(I_{\alpha, \beta, \lambda}^{\mu+1, k} f(z)\right)^{\prime}=\lambda\right]_{\alpha, \beta,}^{\mu, k} f(z)-(\lambda+1) I_{\alpha, \beta, \gamma}^{\mu+1, k} f(z) \\
& z\left(I_{\alpha, \beta, \lambda}^{\mu, k} f(z)\right)^{\prime}=\alpha I_{\alpha, 1, \beta, \lambda}^{\mu, k} f(z)-(\alpha+1) I_{\alpha, \beta, \lambda}^{\mu+1, k} f(z)
\end{aligned}
$$

\section{SUBORDINATION RESULTS INVOLVING THE OPERATOR}

Definition (2.1): Let $\Omega$ be a set in $\mathbb{C}, q(z) \in Q_{1} \cap D[q(0), 1]$. The class of admissible functions $\phi_{n}[\Omega, q]$ consists of those function $\phi: \mathbb{C}^{3} \times U \rightarrow \mathbb{C}$ that satisfy the admissibility condition:

$$
\phi(\mathrm{u}, \mathrm{v}, \mathrm{w} ; \mathrm{z}) \notin \Omega
$$


Whenever:

$$
\begin{aligned}
& \mathrm{u}=\mathrm{q}(\zeta), v=\frac{\mathrm{k} \zeta \mathrm{q}^{\prime}(\zeta)+(\lambda+1) \mathrm{q}(\zeta)}{\lambda} \\
& \operatorname{Re}\left\{\frac{\lambda^{2} \mathrm{w}-(\lambda+1)^{2} \mathrm{u}}{\lambda \nu-(\lambda+1) \mathrm{u}}-2 \lambda\right\} \geq \mathrm{k} \operatorname{Re}\left\{\frac{\zeta \mathrm{q}^{\prime \prime}(\zeta)}{\mathrm{q}^{\prime}(\zeta)}+1\right\} \\
& \mathrm{z} \in \mathrm{U}, \zeta \in \partial \mathrm{U} \backslash \mathrm{E}(\mathrm{q}), \mathrm{k} \geq 1
\end{aligned}
$$

Theorem (2.2): Let $\phi \in \phi_{\mathrm{n}}[\Omega, \mathrm{q}]$. If $\mathrm{f}(\mathrm{z}) \in \mathrm{A}$ satisfies:

$$
\left\{\phi\left(I_{\alpha, \beta, \lambda}^{\mu+1, k} f(z),,_{\alpha, \beta, \lambda}^{\mu, k} f(z), I_{\alpha, \beta, \lambda}^{\mu-1, k} f(z) ; z\right): z \in U\right\} \subset \Omega
$$

Then:

$$
I_{\alpha, \beta, \lambda}^{\mu+1, k} f(z) \prec q(z)
$$

Proof: Define the analytic function $\mathrm{J}(\mathrm{z})$ in $\mathrm{U}$ by:

$$
\mathrm{J}(\mathrm{z})=\mathrm{I}_{\alpha, \beta, \lambda}^{\mu+1, k} \mathrm{f}(\mathrm{z})
$$

In view of relation:

$$
z\left(I_{\alpha, \beta, \lambda}^{\mu+1, k} \mathrm{f}(z)\right)^{\prime}=\lambda \alpha_{\alpha, \beta, \gamma}^{\mu \mathrm{k}} \mathrm{f}(\mathrm{z})-(\lambda+1) \mathrm{I}_{\alpha, \beta, \lambda}^{\mu+1, \mathrm{k}} \mathrm{f}(\mathrm{z})
$$

From Eq. 10 we have:

$$
\mathrm{I}_{\alpha, \beta, \lambda}^{\mu, \mathrm{k}} \mathrm{f}(\mathrm{z})=\frac{1}{\lambda}\left[\mathrm{zJ}^{\prime}(\mathrm{z})+(\lambda+1) \mathrm{J}(\mathrm{z})\right]
$$

Further, a simple computation shows that:

$$
\mathrm{I}_{\alpha, \beta, \beta}^{\mu 1, \mathrm{k}} \mathrm{f}(\mathrm{z})=\frac{1}{\lambda^{2}}\left[\mathrm{z}^{2} \mathrm{~J}^{\prime \prime}(\mathrm{z})+(2 \lambda+3) \mathrm{zJ}(\mathrm{J})+(\lambda+1)^{2} \mathrm{~J}(\mathrm{z})\right]
$$

Define the transformations from $\mathbb{C}^{3}$ to $\mathbb{C b y}$ :

$$
\begin{aligned}
& \mathrm{u}(\mathrm{r}, \mathrm{s}, \mathrm{t})=\mathrm{r}, v(\mathrm{r}, \mathrm{s}, \mathrm{t})=\frac{1}{\lambda}[\mathrm{s}+(\lambda+1) \mathrm{r}] \\
& \mathrm{w}(\mathrm{r}, \mathrm{s}, \mathrm{t})=\frac{1}{\lambda^{2}}\left[\mathrm{t}+(2 \lambda+3) \mathrm{s}+(\lambda+1)^{2} \mathrm{r}\right]
\end{aligned}
$$

Let:

$$
\psi(\mathrm{r}, \mathrm{s}, \mathrm{t} ; \mathrm{z})=\phi(\mathrm{u}, v, \mathrm{w} ; \mathrm{z})=\phi\left(\begin{array}{l}
\mathrm{r}, \frac{1}{\lambda}[\mathrm{s}+(\lambda+1) \mathrm{r}], \\
\frac{1}{\lambda^{2}}\left[\mathrm{t}+(2 \lambda+3) \mathrm{s}+(\lambda+1)^{2} \mathrm{r}\right] ; \mathrm{z}
\end{array}\right)
$$

The proof shall make use of theorem (Eq. 4). Using (Eq. 10, 12 and 13), from (Eq. 15), we obtain:

$$
\begin{aligned}
& \psi\left(J(z), z J^{\prime}(z), z^{2} J^{\prime \prime}(z) ; z\right)= \\
& \phi\left(I_{\alpha, \beta, \lambda}^{\mu+1, k} f(z),{ }_{\alpha, \beta, \lambda}^{\mu, k, k} f(z), I_{\alpha, \beta, \lambda}^{\mu-1, k, k} f(z) ; z\right)
\end{aligned}
$$

Hence, (19) becomes:

$$
\begin{aligned}
& \phi\left(I_{\alpha, \beta, \lambda}^{\mu+1, k} f(z),{ }_{\alpha, \beta, \lambda}^{\mu, k} f(z),,_{\alpha, \beta, \lambda}^{\mu 1, k} f(z) ; z\right)= \\
& \psi\left(J(z), z J^{\prime}(z), z^{2} J^{\prime \prime}(z) ; z\right) \in \Omega
\end{aligned}
$$

Note that:

$$
\frac{\mathrm{t}}{\mathrm{s}}+1=\frac{\lambda^{2} \mathrm{w}-(\lambda+1)^{2} \mathrm{u}}{\lambda v-(\lambda+1) \mathrm{u}}-2 \lambda
$$

And since, the admissibility condition for $\phi \in \Phi_{n}[\Omega, q]$ is equivalent to the admissibility condition for $\psi$ as given in definition (1.2), hence, $\psi \in \Psi[\Omega, q]$ and by theorem (1.4) then $\mathrm{J}(\mathrm{z}) \prec \mathrm{q}(\mathrm{z})$ or $\mathrm{I}_{\alpha, \beta, \lambda}^{\mu+1, \mathrm{k}} \mathrm{f}(\mathrm{z}) \prec \mathrm{q}(\mathrm{z})$.

Theorem (2.3): Let $\phi \in \Phi_{\mathrm{n}}[\mathrm{h}, \mathrm{q}]$ with $\mathrm{q}(0)=1$. If $\mathrm{f}(\mathrm{z}) \in \mathrm{A}$ satisfies:

$$
\phi\left(I_{\alpha, \beta, \lambda}^{\mu+1, k} f(z), I_{\alpha, \beta, \lambda}^{\mu, k} f(z), I_{\alpha, \beta, \lambda}^{\mu-1, k} f(z) ; z\right) \prec h(z)
$$

Then:

$$
\mathrm{I}_{\alpha, \beta, \lambda}^{\mu+1, k} \mathrm{f}(\mathrm{z}) \prec \mathrm{q}(\mathrm{z})(\mathrm{z} \in \mathrm{U})
$$

Our next result is an extension of theorem (2.2) to the case the behavior of $\mathrm{q}(\mathrm{z})$ on $\partial \mathrm{U}$ is not known.

Corollary (2.4): Let $\Omega \subset \mathbb{C}$ and let $q(z)$ be univalent in $U$ with $\mathrm{q}(0)=1$. Let $\phi \in \Phi_{\mathrm{n}}\left[\Omega, \mathrm{q}_{\mathrm{p}}\right]$ for some $\mathrm{p} \in(0,1)$ where $\mathrm{q}_{\mathrm{p}}(\mathrm{z})=\mathrm{q}(\mathrm{pz})$. If $\mathrm{f}(\mathrm{z}) \in \mathrm{A}$ and:

$$
\phi\left(\left(_{\alpha, \beta, \lambda}^{\mu+, k} f(z), I_{\alpha, \beta, \lambda}^{\mu, k} f(z), I_{\alpha, \beta, \lambda}^{\mu-1, k} f(z) ; z\right) \in \Omega\right.
$$

Then:

$$
\mathrm{I}_{\alpha, \beta, \lambda}^{\mu+1, k} \mathrm{f}(\mathrm{z}) \prec \mathrm{q}(\mathrm{z})(\mathrm{z} \in \mathrm{U})
$$

Proof: By theorem (2.2), we get $I_{\alpha, \beta, \lambda}^{\mu+1, k} f(z) \prec q(z)$. The result is now deduced from the following subordination relationship:

$$
\mathrm{q}_{\mathrm{p}}(\mathrm{z}) \prec \mathrm{q}(\mathrm{z})(\mathrm{z} \in \mathrm{U})
$$

In the particular case $\mathrm{q}(\mathrm{z})=\mathrm{Mz}, \mathrm{M}>0$ and in view of definition (2.1), the class of admissible functions $\Phi_{n}[\Omega, q]$ denoted by $\Phi_{\mathrm{n}}[\Omega, \mathrm{M}]$ is described below.

Definition (2.5): Let $\Omega$ be a set in $\mathbb{C}$ and $M>0$. The class of admissible functions $\Phi_{n}[\Omega, M]$ consists of those functions $\varphi: \mathbb{C}^{3} \times \mathrm{U} \rightarrow \mathbb{C}$ such that: 


$$
\phi\left(\begin{array}{l}
\mathrm{Me}^{\mathrm{i} \theta}, \frac{1}{\lambda}[\mathrm{k}+\lambda+1] \mathrm{Me}^{\mathrm{i} \theta}, \\
\frac{1}{\lambda^{2}}\left[1+\left[\mathrm{k}(2 \lambda+3)+(\lambda+1)^{2}\right] \mathrm{Me}^{\mathrm{i} \theta} ; \mathrm{z}\right.
\end{array}\right) \notin \Omega
$$

Whenever $\mathrm{z} \in \mathrm{U}, \mathrm{k} \geq 1, \operatorname{Re}\left(\mathrm{Le}^{-i \theta}\right) \geq(\mathrm{k}-1) \mathrm{kM}$ and $\theta \in \mathrm{R}$ :

Corollary (2.6): Let $\phi \in \Phi_{n}[\Omega, M]$. If $\mathrm{f}(\mathrm{z}) \in \mathrm{A}$ satisfy the following inclusion relationship:

$$
\phi\left(I_{\alpha, \beta, \lambda}^{\mu+1, k} f(z), I_{\alpha, \beta, \lambda}^{\mu, k} f(z), \mu_{\alpha, \beta, \lambda}^{\mu-1, k} f(z) ; z\right) \in \Omega
$$

Then:

$$
\mathrm{I}_{\alpha, \beta, \lambda}^{\mu+1, k} \mathrm{f}(\mathrm{z}) \prec \mathrm{Mz}(\mathrm{z} \in \mathrm{U})
$$

In the special case $\Omega=\mathrm{q}(\mathrm{U})=\{\mathrm{w}:|\mathrm{w}|<\mathrm{M}\}$ the class $\Phi_{n}[\Omega, M]$ is simply denoted by $\Phi_{n}[M]$.

Corollary (2.7): Let $\phi \in \Phi_{n}[M]$. If $f(z) \in A$ satisfies the following inclusion relationship:

$$
\phi\left(I_{\alpha, \beta, \lambda}^{\mu+1, k} f(z), I_{\alpha, \beta,}^{\mu, k} f(z), I_{\alpha, \beta, \lambda}^{\mu, 1, k} f(z) ; z\right)<M
$$

Then:

$$
\left|\mathrm{I}_{\alpha, \beta, \lambda}^{\mu+1, k} \mathrm{f}(\mathrm{z})\right|<\mathrm{M}
$$

Definition (2.8): Let $\Omega$ be a set in $\mathbb{C}, q(z) \in Q \cap D[q(0), 1]$. The class of admissible functions $\Phi_{n, 1}[\Omega, q]$ consists of those functions $\phi: \mathbb{C}^{3} \times U \rightarrow \mathbb{C}$ that satisfy the admissibility condition $\phi(\mathrm{u}, v, \mathrm{w} ; \mathrm{z}) \notin \Omega$ whenever:

$$
\begin{aligned}
& \mathrm{u}=\mathrm{q}(\zeta), v=\frac{1}{\lambda}\left\{\frac{\mathrm{k} \zeta \mathrm{q}^{\prime}(\zeta)}{\mathrm{q}(\zeta)}+\lambda \mathrm{q}(\zeta)\right\},(\mathrm{q}(\zeta) \neq 0) \\
& \operatorname{Re}\left\{\frac{v[2(\lambda+1)+\lambda(\mathrm{w}-\mathrm{v})]}{v-\mathrm{u}}+\lambda(v-2 \mathrm{u})\right\} \geq \mathrm{k} \operatorname{Re}\left\{\frac{\zeta \mathrm{q}^{\prime \prime}(\zeta)}{\mathrm{q}^{\prime}(\zeta)}+1\right\} \\
& \mathrm{z} \in \mathrm{U}, \zeta \in \partial \mathrm{U} \backslash \mathrm{q}(\mathrm{q}), \mathrm{k} \geq 1
\end{aligned}
$$

Theorem (2.9): Let $\phi \in \Phi_{n, 1}[\Omega, q]$. If $\mathrm{f}(\mathrm{z}) \in \mathrm{A}$ satisfies:

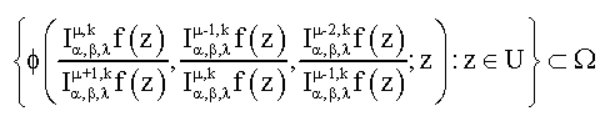

Then:

$$
\frac{I_{\alpha, \beta, f}^{\mu, k}, f(z)}{I_{\alpha, \beta, j}^{\mu+, k} f(z)} \prec q(z)
$$

Proof: Define the analytic function $\mathrm{J}(\mathrm{z})$ in $\mathrm{U}$ by:

$$
J(z)=\frac{I_{\alpha, \beta, \lambda}^{\mu, k} f(z)}{I_{\alpha, \beta, \lambda}^{\mu+, k} f(z)} \prec q(z)
$$

Then, by using (1.7), we get:

$$
\frac{\mathrm{I}_{\alpha, \beta}^{\mu-1, \mathrm{k}} \mathrm{f}(\mathrm{z})}{\mathrm{I}_{\alpha, \beta, \beta}^{\mu, \mathrm{k}} \mathrm{f}(\mathrm{z})}=\frac{1}{\lambda}\left\{\frac{\mathrm{z \textrm {J } ^ { \prime }}(\mathrm{z})}{\mathrm{J}(\mathrm{z})}+\lambda \mathrm{J}(\mathrm{z})\right\}
$$

Differentiating logarithmically (Eq. 22) and further computations show that:

$$
\frac{I_{\alpha, \beta, \lambda}^{\mu-2, k} f(z)}{I_{\alpha, \beta, \lambda}^{\mu-1, k} f(z)}=\frac{1}{\lambda}\left\{\begin{array}{l}
-2(\lambda+1) \frac{z J^{\prime}(z)}{J(z)}+\lambda J(z)+\frac{1}{\frac{z J^{\prime}(z)}{J(z)}+\lambda J(z)} \\
{\left[\frac{z J^{\prime}(z)}{J(z)}+\frac{z^{2} J^{\prime \prime}(z)}{J(z)}-\left(\frac{z J^{\prime}(z)}{J(z)}\right)^{2}+\lambda z J^{\prime}(z)\right.}
\end{array}\right\}
$$

Define the transformations from $\mathbb{C}^{3}$ to $\mathbb{C}$ by:

$$
\begin{aligned}
& \mathrm{u}(\mathrm{r}, \mathrm{s}, \mathrm{t})=\mathrm{r}, \quad v(\mathrm{r}, \mathrm{s}, \mathrm{t})=\frac{1}{\lambda}\left\{\frac{\mathrm{s}}{\mathrm{r}}+\lambda \mathrm{r}\right\} \mathrm{w}(\mathrm{r}, \mathrm{s}, \mathrm{t})= \\
& \frac{1}{\lambda}\left\{-2(\lambda+1)+\frac{\mathrm{s}}{\mathrm{r}}+\lambda \mathrm{r}+\frac{1}{\frac{\mathrm{s}}{\mathrm{r}}+\lambda \mathrm{r}}\left[\frac{\mathrm{s}}{\mathrm{r}}+\frac{\mathrm{t}}{\mathrm{r}}-\left(\frac{\mathrm{s}}{\mathrm{r}}\right)^{2}+\lambda \mathrm{s}\right]\right\}
\end{aligned}
$$

Let:

$$
\begin{gathered}
\psi(\mathrm{r}, \mathrm{s}, \mathrm{t} ; \mathrm{z})=\phi(\mathrm{u}, v, \mathrm{w} ; \mathrm{z}) \\
\phi\left(\mathrm{r}, \frac{1}{\lambda}\left\{\frac{\mathrm{s}}{\mathrm{r}}+\lambda \mathrm{r}\right\}, \frac{1}{\lambda}\left\{\begin{array}{l}
-2(\lambda+1)+\frac{\mathrm{s}}{\mathrm{r}}+\lambda \mathrm{r}+ \\
\frac{1}{\frac{\mathrm{s}}{\mathrm{r}}+\lambda \mathrm{r}}\left[\frac{\mathrm{s}}{\mathrm{r}}+\frac{\mathrm{t}}{\mathrm{r}}\left(\frac{\mathrm{s}}{\mathrm{r}}\right)^{2}+\lambda \mathrm{s}\right.
\end{array}\right] ; \mathrm{z}\right)
\end{gathered}
$$

Using (Eq. 21, 22 and 23), from (Eq. 25), it follows that:

$$
\begin{aligned}
& \psi\left(J(z), J^{\prime}(z), z^{2} J^{\prime \prime}(z) ; z\right)= \\
& \phi\left(\frac{I_{\alpha, \beta, \lambda}^{\mu, k} f(z)}{I_{\alpha, \beta, \lambda}^{\mu+1, k} f(z)}, \frac{I_{\alpha, \beta, \lambda}^{\mu-1, k} f(z)}{I_{\alpha, \beta, \lambda}^{\mu k} f(z)}, \frac{I_{\alpha, \beta, \lambda}^{\mu-\mu, k} f(z)}{I_{\alpha, \beta, \lambda}^{\mu-1, k} f(z)} ; z\right)
\end{aligned}
$$

Hence, (Eq. 20) $\psi\left(\mathrm{J}(\mathrm{z}), \mathrm{zJ}^{\prime}(\mathrm{z}), \mathrm{z}^{2} \mathrm{~J}^{\prime \prime}(\mathrm{z})\right.$; z) $\in \Omega$. The proof is complete if it can be shown that the admissibility condition for $\phi \in \Phi_{n, 1}[\Omega, q]$ is equivalent to the admissibility condition for $\psi$ as given in definition (1.2). For this purpose, note that:

$$
\frac{\mathrm{t}}{\mathrm{s}}+1=\frac{v[2(\lambda+1)+\lambda(\mathrm{w}-\mathrm{v})]}{v-\mathrm{u}}+\lambda(v-2 \mathrm{u})
$$


Hence, $\psi \in \Psi[\Omega, q]$ and by theorem (1.4), we have $\mathrm{J}(\mathrm{z}) \prec \mathrm{q}(\mathrm{z})$ or:

$$
\frac{I_{\alpha, \beta, \gamma}^{\mu, k} f(z)}{I_{\alpha, \beta, \lambda}^{\mu+, k} f(z)} \prec q(z)
$$

In the case $\Omega \neq \mathbb{C}$ is a simply connected domain with $\Omega=h(U)$ for some conformal mapping $h(z)$ of $U$ on to $\Omega$, the class $\Phi_{\mathrm{n}, 1}\left[\mathrm{~h}(\mathrm{U})\right.$, q] is written as $\Phi_{\mathrm{n}, 1}[\mathrm{~h}, \mathrm{q}]$. The following result is an immediate consequence of theorem (2.9).

Theorem (2.10): Let $\phi \in \Phi_{\mathrm{n}, 1}[\mathrm{~h}(\mathrm{U}), \mathrm{q}]$ with $\mathrm{q}(0)=1$, if $\mathrm{f}(\mathrm{z}) \in$ A satisfies the following inclusion relationship:

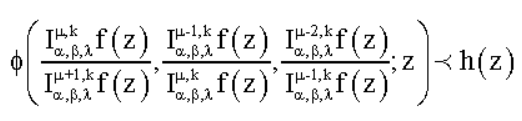

Then:

$$
\frac{I_{\alpha, \beta, \lambda}^{\mu, k} f(z)}{I_{\alpha, \beta, \lambda}^{\mu+1, k} f(z)} \prec q(z)
$$

In the particular case $q(z)=M z, M>0$. The class of admissible function $\Phi_{\mathrm{n}, 1}[\Omega, \mathrm{q}]$, denoted by $\Phi_{\mathrm{n}, 1}[\Omega, \mathrm{M}]$ is described below.

Definition (2.11): Let $\Omega$ be a set in $\mathbb{C}$ and $M>0$. The class of admissible functions $\Phi_{n, 1}[\Omega, M]$ consists of those functions $\phi: \mathbb{C}^{3} \times U \rightarrow \mathbb{C}$ such that:

$$
\left.\phi\left(\begin{array}{l}
\mathrm{Me}^{\mathrm{i} \theta}, \frac{1}{\lambda}\left\{\mathrm{k}+\lambda \mathrm{Me}^{\mathrm{i} \theta}\right\}, \frac{1}{\lambda} \\
-2(\lambda+1)+\mathrm{k}+\lambda \mathrm{Me} \mathrm{e}^{\mathrm{i} \theta}+\frac{1}{\mathrm{kM}+\lambda \mathrm{M}^{2} \mathrm{e}^{\mathrm{i} \theta}}
\end{array}\right\} ; \mathrm{Z}\right) \notin \Omega
$$

Whenever and.

Corollary (2.12): Let $\phi \in \Phi_{\mathrm{n}, 1}[\Omega, \mathrm{M}]$. If $\mathrm{f}(\mathrm{z}) \in \mathrm{A}$ satisfies:

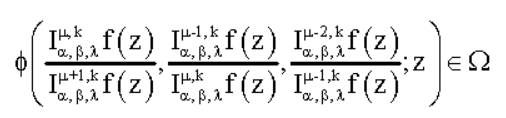

Then:

$$
\frac{I_{\alpha, \beta, \pi}^{\mu, \mathrm{k}} \mathrm{f}(\mathrm{z})}{\mathrm{I}_{\alpha, \beta, \lambda}^{\mu+1, \mathrm{k}} \mathrm{f}(\mathrm{z})} \prec \mathrm{Mz}(\mathrm{z} \in \mathrm{U})
$$

In the special case $\Omega=q(U)=\{w:|q|<M\}$, the class $\Phi_{\mathrm{n}, 1}[\Omega, \mathrm{M}]$ is defined by $\Phi_{\mathrm{n}, 1}[\mathrm{M}]$ and corollary (2.12) takes follows for:
Corollary (2.13): Let $\phi \in \Phi_{\mathrm{n}, 1}[\mathrm{M}]$. If $\mathrm{f}(\mathrm{z}) \in$ A satisfies:

$$
\left|\phi\left(\frac{I_{\alpha, \beta, \lambda}^{\mu-1, k} f(z)}{I_{\alpha, \beta, \lambda}^{\mu,} f(z)}, \frac{I_{\alpha, \beta, \beta}^{\mu-1, k} f(z)}{I_{\alpha, \beta, \lambda}^{\mu, k} f(z)}, \frac{I_{\alpha, \beta}^{\mu-2, k} f(z)}{I_{\alpha, \beta, \lambda}^{\mu-1, k} f(z)} ; z\right)\right|<M
$$

Then:

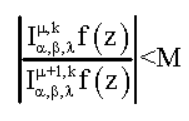

\section{SUPERORDINATION RESULTS INVOLVING THE OPERATOR $I_{\alpha, \beta, \lambda}^{\mu, k} f(z)$}

In this section we obtain differential super ordination for the operator $I_{\alpha, \beta, \gamma}^{\mu, k} f(z)$. For this purpose the class of admissible functions is given in the following definition.

Definition (3.1): Let $\Omega$ be a set in $\mathbb{C}, \mathrm{q}(\mathrm{z}) \in \mathrm{D}[\mathrm{q}(0), 1]$ with $\mathrm{zq}^{\prime}(\mathrm{z}) \neq 0$. The class of admissible functions $\Phi_{\mathrm{n}}^{\prime}[\Omega, \mathrm{q}]$ consists of those function $\phi: \mathbb{C}^{3} \times \overline{\mathrm{U}} \rightarrow \mathbb{C}$ that satisfy the admissibility condition:

$$
\phi(\mathrm{u}, \mathrm{v}, \mathrm{w} ; \zeta) \in \Omega
$$

Whenever:

$$
\begin{gathered}
u=q(z), \quad v=\frac{z q^{\prime}(z)+m(\lambda+1) q(z)}{m \lambda} \\
\operatorname{Re}\left\{\frac{\lambda^{2} w-(\lambda+1)^{2} u}{\lambda v-(\lambda+1) u}\right\} \leq \frac{1}{m} \operatorname{Re}\left\{\frac{z q^{\prime \prime}(z)}{q^{\prime}(z)}+1\right\} \\
z \in U, \zeta \in \partial U, m \geq 1
\end{gathered}
$$

Theorem (3.2): Let $\phi \in \Phi_{n}^{\prime}[\Omega, q]$. If $f(z) \in A, \quad I_{\alpha, \beta, \lambda}^{\mu+, k} f(z) \in Q_{1}$ and $\phi\left(I_{\alpha, \beta, \lambda}^{\mu+1, k} \mathrm{f}(\mathrm{z}), I_{\alpha, \beta, \lambda}^{\mu, k} \mathrm{f}(\mathrm{z}), \mathrm{N}_{\alpha, \beta, \lambda}^{\mu-1, k} \mathrm{f}(\mathrm{z}) ; \mathrm{z}\right)$ is univalent in then:

$$
\Omega \subset\left\{\phi\left(\mathrm{I}_{\alpha, \beta, \lambda}^{\mu+1, \mathrm{k}} \mathrm{f}(\mathrm{z}), \mathrm{I}_{\alpha, \beta, \lambda}^{\mu \mathrm{\mu}} \mathrm{f}(\mathrm{z}), \mathrm{I}_{\alpha, \beta, \lambda}^{\mu-1, \mathrm{k}} \mathrm{f}(\mathrm{z}) ; \mathrm{z}\right): \mathrm{z} \in \mathrm{U}\right\}
$$

Implies:

$$
\mathrm{q}(\mathrm{z}) \prec \mathrm{I}_{\alpha, \beta, \lambda}^{\mu+1, \mathrm{k}} \mathrm{f}(\mathrm{z})
$$

Proof : Let J(z) define by (2.2) and $\psi(\mathrm{z})$ define by (2.8). Since, $\phi \in \Phi_{n}^{\prime}[\Omega, q]$ from (2.2) and (3.1) we have:

$$
\Omega \subset\left\{\psi\left(\mathrm{J}(\mathrm{z}), \mathrm{zJ}^{\prime}(\mathrm{z}), \mathrm{z}^{2} \mathrm{~J}^{\prime \prime}(\mathrm{z}) ; \mathrm{z}\right): \mathrm{z} \in \mathrm{U}\right\}
$$

From (2.7), we see that the admissibility condition for $\phi \in \Phi_{n}^{\prime}[\Omega, q]$ is equivalent to the admissibility condition for 
$\psi$ as given in definition (1.2). Hence, $\psi \in \Psi^{\prime}[\Omega, \mathrm{q}]$ and by and by theorem (1.4), we have $\mathrm{q}(\mathrm{z})<\mathrm{J}(\mathrm{z})$ or $\mathrm{q}(\mathrm{z}) \prec \mathrm{I}_{\alpha, \beta, \pi}^{\mathrm{I}, \mathrm{k}, \mathrm{f}} \mathrm{f}(\mathrm{z})$.

In the case $\Omega \neq \mathbb{C}$ is a simply connected domain with $\Omega=h(U)$ for some conformal mapping h(z) of $U$ on to $\Omega$, the class $\Phi_{n, 1}^{\prime}\left[h(U)\right.$, q] is written as $\Phi_{n, 1}^{\prime}[h, q]$. The following result is an immediate consequence of theorem (3.2).

Theorem (3.3): Let $q(z) \in D, h(z)$ is analytic on $U$ and $\phi \in \Phi_{n}^{\prime}[\Omega, q]$. If $f(z) \in A, I_{\alpha, \beta, \lambda}^{\mu+1, k} f(z) \in Q_{1}$ and:

$$
\phi\left(I_{\alpha, \beta, \lambda}^{\mu+1, k} f(z), I_{\alpha, \beta, \lambda}^{\mu, \mathrm{k}} \mathrm{f}(\mathrm{z}), \mathrm{I}_{\alpha, \beta, \lambda}^{\mu-1, \mathrm{k}} \mathrm{f}(\mathrm{z}) ; \mathrm{z}\right)
$$

Is univalent in then:

$$
h(z) \prec \phi\left(I_{\alpha, \beta, \lambda}^{\mu+1, k} f(z), I_{\alpha, \beta, \lambda}^{\mu, k} f(z), I_{\alpha, \beta, \lambda}^{\mu-1, k} f(z) ; z\right)
$$

Implies:

$$
\mathrm{q}(\mathrm{z}) \prec \mathrm{I}_{\alpha, \beta, \lambda}^{\mu+1, \mathrm{k}} \mathrm{f}(\mathrm{z})
$$

Combining theorem (2.3) and (3.3), we obtain the following sandwich theorem.

Corollary (3.4): Let $h_{1}(z)$ and $\mathrm{q}_{1}(\mathrm{z})$ be analytic functions in $\mathrm{U}, \mathrm{h}_{2}(\mathrm{z})$ be univalent function in $\mathrm{U}, \mathrm{h}_{2}(\mathrm{z}) \in \mathrm{Q}_{1}$ with $\mathrm{q}_{1}(0)=\mathrm{q}_{2}(0)=1$ and $\phi \in \Phi_{\mathrm{n}}\left[\mathrm{h}_{2}, \mathrm{q}_{2}\right] \cap \Phi_{\mathrm{n}}\left[\mathrm{h}_{1}, \mathrm{q}_{1}\right]$. If $\mathrm{f}(\mathrm{z}) \in \mathrm{A}, \mathrm{I}_{\alpha, \beta, \beta}^{\mu+1, k} \mathrm{f}(\mathrm{z}) \in \mathrm{D} \cap \mathrm{Q}_{1}$ and:

$$
\phi\left(I_{\alpha, \beta, \lambda}^{\mu+1, k} f(z), I_{\alpha, \beta, \lambda}^{\mu, k} f(z), I_{\alpha, \beta, \lambda}^{\mu-1, k} f(z) ; z\right)
$$

Is univalent in $\mathrm{U}$ then:

$$
h_{1}(z) \prec \phi\left(I_{\alpha, \beta, \lambda}^{\mu+1, k} f(z), I_{\alpha, \beta, \lambda}^{\mu, k} f(z), I_{\alpha, \beta, \lambda}^{\mu-1, k} f(z) ; z\right) \prec h_{2}(z)
$$

Implies:

$$
\mathrm{q}_{1}(\mathrm{z}) \prec \mathrm{I}_{\alpha, \beta, \lambda}^{\mu+1, k} \mathrm{f}(\mathrm{z}) \prec \mathrm{q}_{2}(\mathrm{z})
$$

Definition (3.5): Let $\Omega$ be a set in $\mathbb{C}, q(z) \in D[q(0), 1]$ with $\mathrm{zq}^{\prime}(\mathrm{z}) \neq 0$. The class of admissible functions $\Phi_{\mathrm{n}, 1}^{\prime}[\Omega, \mathrm{q}]$ consists of those function $\phi: \mathbb{C}^{3} \times \overline{\mathrm{U}} \rightarrow \mathbb{C}$ that satisfy the admissibility condition:

$$
\phi(\mathrm{u}, \mathrm{v}, \mathrm{w} ; \zeta) \notin \Omega
$$

Whenever:

$$
\mathrm{u}=\mathrm{q}(\mathrm{z}), v=\frac{1}{\lambda}\left\{\frac{\mathrm{kzq}(\mathrm{z})}{\mathrm{mq}(\mathrm{z})}+\lambda \mathrm{q}(\mathrm{z})\right\},(\mathrm{q}(\mathrm{z}) \neq 0)
$$

$$
\begin{gathered}
\operatorname{Re}\left\{\frac{\mathrm{v}[2(\lambda+1)+\lambda(\mathrm{w}-\mathrm{v})]}{\mathrm{v}-\mathrm{u}}+\lambda(\mathrm{v}-2 \mathrm{u})\right\} \leq \frac{1}{\mathrm{~m}} \operatorname{Re}\left\{\frac{\mathrm{zq}(\mathrm{z})}{\mathrm{q}^{\prime}(\mathrm{z})}+1\right\} \\
\mathrm{z} \in \mathrm{U}, \zeta \in \partial \mathrm{U} \mathrm{E}(\mathrm{q}), \mathrm{m} \geq 1
\end{gathered}
$$

Now, we will give the dual result of theorem (2.9) for differential superordination.

Theorem (3.6): Let $\phi \in \Phi_{n, 1}[\Omega, q]$. If $f(z) \in A,{ }_{\alpha, \beta, \lambda}^{\mu+1, k} f(z) \in Q_{1}$ and:

$$
\phi\left(\frac{I_{\alpha, \beta, \lambda}^{\mu, k} f(z)}{I_{\alpha, \beta, \lambda}^{\mu+1, k} f(z)} \frac{I_{\alpha, \beta, \lambda}^{\mu-1, k} f(z)}{I_{\alpha, \beta, \lambda}^{\mu, k} f(z)}, \frac{I_{\alpha, \beta}^{\mu-2, k} f(z)}{I_{\alpha, \beta, \lambda}^{\mu-1, k} f(z)} ; z\right)
$$

Is univalent in $\mathrm{U}$, then:

$$
\Omega \subset\left\{\phi\left(\frac{I_{\alpha, \beta, \lambda}^{\mu, k} f(z)}{I_{\alpha, \beta, \lambda}^{\mu+1, k} f(z)}, \frac{I_{\alpha, \beta, \lambda}^{\mu-1, k} f(z)}{I_{\alpha, \beta, \lambda}^{\mu, k} f(z)}, \frac{I_{\alpha, \beta, \lambda}^{\mu-2, k} f(z)}{I_{\alpha, \beta, \lambda}^{\mu-1, k} f(z)} ; z\right): z \in U\right\}
$$

Implies:

$$
q(z) \prec \frac{I_{\alpha, \beta, \lambda}^{\mu, k} f(z)}{I_{\alpha, \beta, \lambda}^{\mu+1, k} f(z)}
$$

Proof: Let J(z) define by (2.13) and $\psi(z)$ define by. Since, $\phi \in \Phi_{\mathrm{n}, 1}^{\prime}[\Omega, q]$ from (Eq. 25) and (29) we have:

$$
\Omega \subset\left\{\psi\left(\mathrm{J}(\mathrm{z}), \mathrm{zJ}^{\prime}(\mathrm{z}), \mathrm{z}^{2} \mathrm{~J}^{\prime \prime}(\mathrm{z}) ; \mathrm{z}\right): \mathrm{z} \in \mathrm{U}\right\}
$$

From (Eq. 25), we see that the admissibility condition for $\phi \in \Phi_{n, 1}^{\prime}[\Omega, q]$ is equivalent to the admissibility condition for $\psi$ as given in definition (1.3). Hence, $\psi \in \Psi^{\prime}[\Omega, q]$ and by and by theorem (1.5), we have $\mathrm{q}(\mathrm{z})<\mathrm{J}(\mathrm{z})$ or:

$$
q(z) \prec \frac{I_{\alpha, \beta, \lambda}^{\mu, k} f(z)}{I_{\alpha, \beta, \lambda}^{\mu+1, k} f(z)}
$$

In the case $\Omega \neq \mathbb{C}$ is a simply connected domain with $\Omega=h(U)$ for some conformal mapping h(z) of $\mathrm{U}$ on to $\Omega$, the class $\Phi_{n, 1}^{\prime}\left[h(U)\right.$, q] is written as $\Phi_{n, 1}^{\prime}[h, q]$. The following result is an immediate consequence of theorem (3.6).

Theorem (3.7): Let $q(z) \in D, h(z)$ is analytic on $U$ and $\phi \in \Phi_{n, 1}^{\prime}[\Omega, q]$. If $\mathrm{f}(\mathrm{z}) \in \mathrm{A}, \mathrm{I}_{\alpha, \beta, \lambda}^{\mu+1, k} \mathrm{f}(\mathrm{z}) \in \mathrm{Q}_{1}$ and:

$$
\phi\left(\frac{I_{\alpha, \beta, \lambda}^{\mu, k} f(z)}{I_{\alpha, \beta, \lambda}^{\mu+1, k} f(z)}, \frac{I_{\alpha, \beta, \lambda}^{\mu-1, k} f(z)}{I_{\alpha, \beta, \lambda}^{\mu, k} f(z)}, \frac{I_{\alpha, \beta, \lambda}^{\mu-2, k} f(z)}{I_{\alpha, \beta, \lambda}^{\mu-1, k} f(z)} ; z\right)
$$

Is univalent in $\mathrm{U}$, then:

$$
h(z) \prec \phi\left(\frac{I_{\alpha, \beta, \lambda}^{\mu, k} f(z)}{I_{\alpha, \beta, \lambda}^{\mu+1, k} f(z)}, \frac{I_{\alpha, \beta}^{\mu-1, k} f(z)}{I_{\alpha, \beta, \lambda}^{\mu, k} f(z)}, \frac{I_{\alpha, \beta, \lambda}^{\mu-2, k} f(z)}{I_{\alpha, \beta, \lambda}^{\mu-1, k} f(z)} ; z\right)
$$


Implies:

$$
q(z) \prec \frac{I_{\alpha, \beta, \lambda}^{\mu, k} f(z)}{I_{\alpha, \beta, \lambda}^{\mu+, k} f(z)}
$$

Combining theorem (2.10) and (3.7), we obtain the following sandwich-type theorem.

Corollary (3.8): Let $h_{1}(z)$ and $\mathrm{q}_{1}(\mathrm{z})$ be analytic functions in $\mathrm{U}, \mathrm{h}_{2}(\mathrm{z})$ be univalent function in $\mathrm{U}, \mathrm{q}_{2}(\mathrm{z}) \in \mathrm{Q}_{1}$ with $\mathrm{q}_{1}(0)=\mathrm{q}_{2}(0)=1$ and $\phi \in \Phi_{\mathrm{n}, 1}\left[\mathrm{~h}_{2}, \mathrm{q}_{2}\right] \cap \Phi_{\mathrm{n}, 1}\left[\mathrm{~h}_{1}, \mathrm{q}_{1}\right]$. If

$$
\begin{aligned}
& \mathrm{f}(\mathrm{z}) \in \mathrm{A}, \frac{\mathrm{I}_{\alpha, \beta, \lambda}^{\mu, \mathrm{k}} \mathrm{f}(\mathrm{z})}{\mathrm{I}_{\alpha, \beta, \lambda}^{\mu+1, k} \mathrm{f}(\mathrm{z})} \in \mathrm{D} \cap \mathrm{Q}_{1} \text { and: }
\end{aligned}
$$

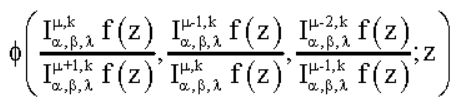

Is univalent in $\mathrm{U}$ then:

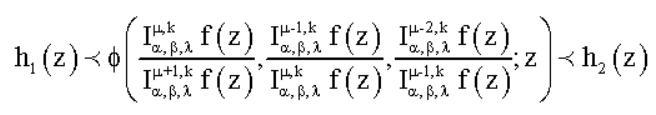

Implies:

$$
\mathrm{q}_{1}(z) \prec \frac{I_{\alpha, \beta, \lambda}^{\mu, k} f(z)}{I_{\alpha, \beta, \lambda}^{\mu+1, k} f(z)} \prec q_{2}(z)
$$

\section{CONCLUSION}

These results are obtained by investigating classes of admissible functions. Some of the results in this study would provide extensions of those given in earlier works.

\section{REFERENCES}

Bulboaca, T., 2005. Differential Subordinations and Superordinations: Recent Results. Casa Cartii De Stiinta S.R.L., Cluj-Napoca, Romania, ISBN: 9789736867774, Pages: 297.

Cho, N.E. and I.H. Kim, 2007. Inclusion properties of certain classes of meromorphic functions associated with the generalized hypergeometric function. Applied Math. Comput., 187: 115-121.

Cho, N.E., O.S. Kwon and H.M. Srivastava, 2004. Inclusion and argument properties for certain subclasses of meromorphic functions associated with a family of multiplier transformations. J. Math. Anal. Appl., 300: 505-520.

Choi, J.H., M. Saigo and H.M. Srivastava, 2002. Some inclusion properties of a certain family of integral operators. J. Math. Anal. Appli., 276: 432-445.
Dziok, J. and H.M. Srivastava, 2002. Some subclasses of analytic functions with fixed argument of coefficients associated with the generalized hypergeometric function. Adv. Stud. Contemp. Math. Kyungshang, 5: $115-125$.

Dziok, J. and H.M. Srivastava, 2003. Certain subclasses of analytic functions associated with the generalized hypergeometric function. Trans. Spec. Funct., 14: 7-18.

Ghanim, F. and M. Darus, 2010a. Some properties of certain subclass of meromorphically multivalent functions defined by linear operator. J. Math. Stat., 6: $34-41$.

Ghanim, F. and M. Darus, 2010b. Some results of p-valentmeromorphic functions defined by a linear operator. Far East J. Math. Sci., 44: 155-165.

Ghanim, F. and M. Darus, 2011a. A new class of meromorphically analytic functions with applications to the generalized hypergeometric functions. Abstr. Applied Anal., Vol. 2011, 10.1155/2011/159405

Ghanim, F. and M. Darus, 2011b. Certain subclasses of meromorphic functions related to Cho-Kwon-Srivastava operator. Far East J. Math. Sci., 48: 159-173.

Liu, J., 2001a. The Noor integral and strongly starlike functions. J. Math. Anal. Appl., 261: 441-447.

Liu, J.L. and H.M. Srivastava, 2001b. A linear operator and associated families of meromorphically multivalent functions. J. Math. Anal. Applied, 259: 566-581.

Liu, J.L. and H.M. Srivastava, 2004a. Certain properties of the Dziok-Srivastava operator. Applied Math. Comput., 159: 485-493.

Liu, J.L. and H.M. Srivastava, 2004b. Classes of meromorphically multivalent functions associated with the generalized hypergeometric function. Math. Comput. Model., 39: 21-34.

Liu, J.L. and K.I. Noor, 2002. Some properties of Noor integral operator. J. Nat. Geom., 21: 81-90.

Liu, J.L., 2003. A linear operator and its applications on meromorphic p-valent functions. Bull. Inst. Math. Acad. Sin., 31: 23-32.

Miller, S.S. and P.T. Mocanu, 2000. Differential Subordinations: Theory and Applications. Marcel Dekker, New York, USA., Pages: 456.

Miller, S.S. and P.T. Mocanu, 2003. Subordinants of differential superordinations. Complex Var., 48: 815-826.

Noor, K.I., 1999. On new classes of integral operators. J. Natur. Geom., 16: 71-80.

Piejko, K. and J. Sokol, 2008. Subclasses of meromorphic functions associated with the Cho-Kwon-Srivastava operator. J. Math. Anal. Appl., 337: 1261-1266. 